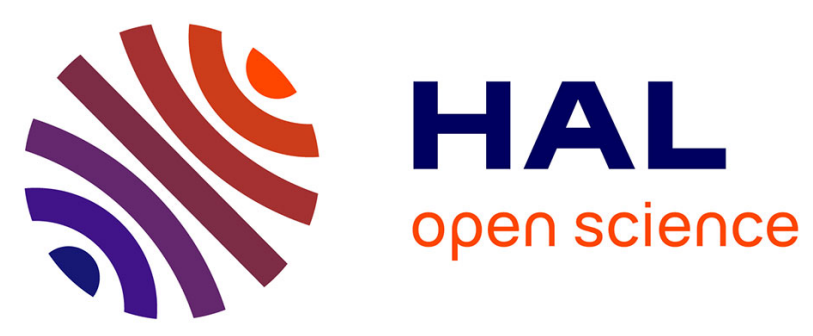

\title{
Futility Risk Model for Predicting Outcome After Transcatheter Aortic Valve Implantation
}

Pierre Lantelme, Thibaud Lacour, Arnaud Bisson, Julien Herbert, Fabrice

Ivanes, Thierry Bourguignon, Laurent Quilliet, Denis Angoulvant, Brahim Harbaoui, Dominique Babuty, et al.

\section{To cite this version:}

Pierre Lantelme, Thibaud Lacour, Arnaud Bisson, Julien Herbert, Fabrice Ivanes, et al.. Futility Risk Model for Predicting Outcome After Transcatheter Aortic Valve Implantation. American Journal of Cardiology, 2020, 130, pp.100-107. 10.1016/j.amjcard.2020.05.043 . hal-03149446

\section{HAL Id: hal-03149446 \\ https://hal-amu.archives-ouvertes.fr/hal-03149446}

Submitted on 23 Feb 2021

HAL is a multi-disciplinary open access archive for the deposit and dissemination of scientific research documents, whether they are published or not. The documents may come from teaching and research institutions in France or abroad, or from public or private research centers.
L'archive ouverte pluridisciplinaire HAL, est destinée au dépôt et à la diffusion de documents scientifiques de niveau recherche, publiés ou non, émanant des établissements d'enseignement et de recherche français ou étrangers, des laboratoires publics ou privés.

\section{(1) (1) $\$$}

Distributed under a Creative Commons Attribution - NonCommercial - NoDerivatives| 4.0 


\title{
Futility Risk Model for Predicting Outcome After Transcatheter Aortic Valve Implantation
}

\author{
Pierre Lantelme, MD, PhD ${ }^{\mathrm{a}, *}$, Thibaud Lacour, $\mathrm{MD}^{\mathrm{b}}$, Arnaud Bisson, $\mathrm{MD}^{\mathrm{b}}$, Julien Herbert, MSc ${ }^{\mathrm{b}, \mathrm{c}}$, \\ Fabrice Ivanes, $\mathrm{MD}, \mathrm{PhD}^{\mathrm{b}}$, Thierry Bourguignon, $\mathrm{MD}, \mathrm{PhD}^{\mathrm{d}}$, Laurent Quilliet, $\mathrm{MD}^{\mathrm{b}}$, \\ Denis Angoulvant, $\mathrm{MD}, \mathrm{PhD}^{\mathrm{b}}$, Brahim Harbaoui, $\mathrm{MD}, \mathrm{PhD}^{\mathrm{a}}$, Dominique Babuty, $\mathrm{MD}, \mathrm{PhD}^{\mathrm{b}}$, \\ Christophe Saint Etienne, $\mathrm{MD}^{\mathrm{b}}$, Pierre Deharo, $\mathrm{MD}, \mathrm{PhD}^{\mathrm{e}}$, Anne Bernard, $\mathrm{MD}, \mathrm{PhD}^{\mathrm{b}}$, and \\ Laurent Fauchier, MD, PHD ${ }^{\mathrm{b}}$
}

\begin{abstract}
Risk-benefit assessment for transcatheter aortic valve implantation (TAVI) is still a matter of debate. We aimed to identify patients with a bad outcome within 1 year after TAVI, and to develop a Futile TAVI Simple score (FTS). Based on the administrative hospital-discharge database, all consecutive patients treated with percutaneous TAVI in France between 2010 and 2018 were included. A prediction model was derived and validated for 1-year all-cause death after TAVI (considered as futility) by using split-sample validation: 20,443 patients were included in the analysis (mean age $83 \pm 7$ years). 7,039 deaths were recorded (yearly incidence rate $15.5 \%$ ), among which 3,702 (53\%) occurred in first year after TAVI procedure. In the derivation cohort $(n=10,221)$, the final logistic regression model included male sex, history of hospital stay with heart failure, history of pulmonary oedema, atrial fibrillation, previous stroke, vascular disease, renal disease, liver disease, pulmonary disease, anaemia, history of cancer, metastasis, depression and denutrition. The area under the curve (AUC) for the FTS was 0.674 (95\% CI 0.660 to 0.687 ) in the derivation cohort and $0.651(95 \% \mathrm{CI} 0.637$ to 0.665$)$ in the validation cohort $(\mathrm{n}=10,222)$. The Hosmer-Lemeshow test had a p-value of 0.87 suggesting an accurate calibration. The FTS score outperformed EuroSCORE II, Charlson comorbidity index and frailty index for identifying futility. Based on FTS score, $7 \%$ of these patients were categorized at high risk with a 1-year mortality at $43 \%$. In conclusion, the FTS score, established from a large nationwide cohort of patients treated with TAVI, may provide a relevant tool for optimizing healthcare decision. () 2020 Elsevier Inc. All rights reserved. (Am J Cardiol 2020;130:100-107)
\end{abstract}

Continuous development has improved the results of transcatheter aortic valve implantation (TAVI) for severe aortic stenosis in high surgical risk patients. ${ }^{1,2}$ Although TAVI provides tremendous survival rate and symptom benefit for most, a sizeable group of patients do not fully benefit from intervention despite a technically successful procedure. The option to consider palliative care instead of a futile invasive procedure for these patients is increasingly recognized. ${ }^{3,4}$ Identifying them should be grounded on predicting post-TAVI outcomes. We previously developed the CAPRI score, a score of futility meant to estimate 1-year all-scause and cardiovascular mortalities after TAVI ${ }^{5}$; it

${ }^{a}$ Fédération de Cardiologie, Hôpital Croix-Rousse et Hôpital Lyon Sud, Hospices Civils de Lyon, Lyon, France; Université de Lyon, CREATIS UMR5220, INSERM U1044, INSA-15 Lyon, France; 'bervice de Cardiologie, Centre Hospitalier Universitaire Trousseau et Faculté de Médecine, Université de Tours, France; ${ }^{\mathrm{c}}$ Service d'information médicale, d'épidémiologie et d'économie de la santé, Centre Hospitalier Universitaire et Faculté de Médecine, Université de Tours, France; ${ }^{\mathrm{d}}$ Service de Chirurgie Cardiaque, Centre Hospitalier Universitaire et Faculté de Médecine, Université de Tours, France; and ${ }^{\mathrm{e}}$ Département de Cardiologie, CHU Timone et Faculté de Médecine, Inserm INRA C2VN, Aix-Marseille Université, Marseille, France. Manuscript received April 9, 2020; revised manuscript received and accepted May 25, 2020.

*Corresponding author: Tel. : (33) 472071 667; fax: (33) 472071674

E-mail address: pierre.lantelme@chu-lyon.fr (P. Lantelme). encompasses thoracic aortic calcification (TAC) as TAC conveys some important prognostic information ${ }^{6}$; yet its determination from the CT scan may be cumbersome with available tools what could limit its implementation. In addition, the CAPRI score does not encompass frailty markers. We feel that there is still room for a futility score based on simple clinical variables that can be universally used. Based on the national hospitalization database, we therefore sought to identify patients with a survival $<1$ year following TAVI and to develop a prediction model and calculator for identification of these patients.

\section{Methods}

This longitudinal cohort study was based on the national hospitalization database covering hospital care from the entire French population. The data for all patients admitted with aortic stenosis in France from January 2008 to December 2018 were collected from the national administrative French Programme de Médicalisation des Systèmes d'Information (PMSI) database. Each hospitalisation is encoded in a standardised dataset, which includes information about the patient (age and sex), hospital, stay, pathologies, and procedures. Routinely collected medical information includes the principal diagnosis and secondary diagnoses coded according to the International Classification of Diseases, Tenth Revision 
(ICD-10). All medical procedures are recorded according to the national nomenclature, Classification Commune des Actes Medicaux (CCAM). The reliability of PMSI data has already been assessed ${ }^{7}$ and this database has previously been used to study patients with cardiovascular conditions, including those with aortic stenosis treated with TAVI. ${ }^{8-11}$ The study was conducted retrospectively and, as patients were not involved in its conduct, there was no impact on their care. Ethical approval was not required, as all data were anonymized. Procedures for data collection and management were approved by the Commission Nationale de l'Informatique et des Libertés, the independent National Ethical Committee protecting human rights in France, which ensures that all information is kept confidential and anonymous (authorisation number 1897139).

From January 1, 2010 to December 31, 2018, 487,085 adults (age $\geq 18$ years) were hospitalised with a diagnosis of aortic stenosis as the principal, related or significantly associated diagnosis. We restricted the analysis to patients admitted after 2010, as this allowed us to obtain at least 2 years of past events to define comorbidities since 2008 . For the analysis of TAVI procedures, we included all adults with a single percutaneous procedure (CCAM code: DBLF001). Patient information (demographics, comorbidities, medical history, procedures and events during hospitalization or follow-up) was described using data collected in the hospital records. Based on the database, we were able to estimate a proxy of the EuroSCORE II (supplemental file). ${ }^{12} \mathrm{We}$ also used the Charlson Comorbidity Index and the Claims-based Frailty Index to assess patients' clinical status. ${ }^{13,14}$ Exclusion criteria were age $<18$ years and TAVI via a nonpercutaneous route; patients alive but with follow up $<1$ year were also excluded. The overall sample of 20,443 patients was randomly partitioned into derivation $(\mathrm{n}=10,221)$ and validation $(\mathrm{n}=10,222)$ populations (Figure 1). Patients were followed until 31 December 2018 for the occurrence of outcomes. We aimed to evaluate the incidence all-cause death, this outcome being included with the Valve Academic Research Consortium-2 consensus document. ${ }^{15}$ The primary end point was procedural futility, defined as 1-year mortality. A prediction model was then derived and validated.

Qualitative variables were described as counts and percentages and quantitative variable as means (standard

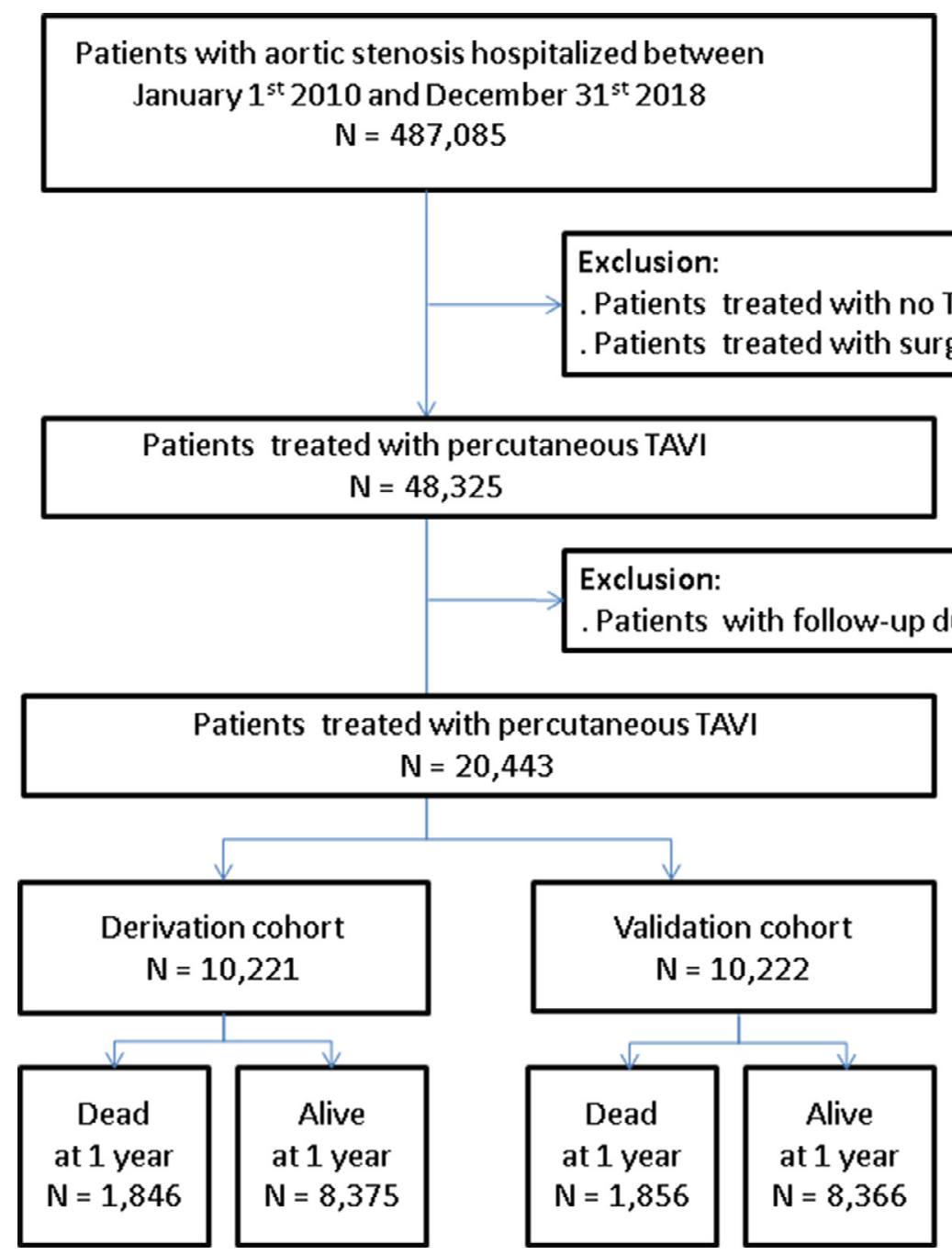

Figure 1. Flow chart of the study population. 
deviations [SDs]). Comparisons were made using chisquare tests for categorical variables and the Student $t$ test or nonparametric Kruskal-Wallis test, as appropriate, for continuous variables. Patients who died during the first year following the procedure were compared to patients alive at 1 year. Multivariate logistic regression was used, and results were expressed as odds ratio (OR) and 95\% confidence intervals $(95 \% \mathrm{CI})$. The Futile TAVI Simple (FTS) score was built using the multivariate logistic regression. To create the score points, the regression coefficients with $\mathrm{p}$ $<0.05$ were divided by the smallest coefficient and rounded to the nearest integer. ${ }^{16,17}$ Receiver operating characteristic (ROC) curves were constructed and the Harrell's C-indexes (i.e., area under the curve) were calculated as a measure of model performance. ROC curves with the EuroSCORE II, Charlson Comorbidity Index and Claims-based Frailty Index were compared using the DeLong test, first in the derivation cohort and then in the validation cohort. Model calibration was considered acceptable at the HosmerLemeshow goodness-of-fit test $\mathrm{p}>0.1$. We then plotted observed versus predicted risks by decile of predicted risk, and the regression line was compared against the line of equality (intercept $=0$, slope $=1$ ). All comparisons with $p$ $<0.05$ were considered statistically significant. Analyses were performed using Enterprise Guide $7 \bullet 1$, (SAS Institute Inc., SAS Campus Drive, Cary, NC) and STATA version 12.0 (Stata Corp, College Station, TX).

\section{Results}

Between January 1, 2010 and December 31, 2018, 20,443 patients with percutaneous TAVI were identified for the analysis (mean age $83 \pm 7$ years). The characteristics of patients in the derivation and validation cohorts are presented in Table 1. Mean follow-up was $2.09 \pm 1.36$ years (median 1.89, interquartile 1.18 to 2.92 ) and 7,039 deaths were recorded (yearly incidence rate $15.5 \%$ ), among which $3,702(53 \%)$ occurred in first year after TAVI procedure ( $18.1 \%$ of all patients with TAVI in our study). In the derivation cohort, patients with all-cause death during the first year of follow-up were more frequently men and had higher EuroSCORE II, Charlson comorbidity and frailty indexes. They also had higher rates for most comorbidities (Table 2). Among patients excluded of the main analysis, 77,325 had surgical aortic valve replacement (1-year death rate $7.95 \%$ ) and 3,360 had surgical TAVI with apical access (1-year death rate $24.72 \%$ ).

The final logistic regression model for futility included older age, history of hospital stay with heart failure, history of pulmonary oedema, atrial fibrillation, previous stroke, vascular disease, renal disease, liver disease, pulmonary disease, anaemia, history of cancer, metastasis, depression, and denutrition. The model is presented in Table 3, with corresponding points for each variable. The area under the curve (AUC) for the FTS score was 0.674 (95\% CI 0.660 to 0.687). The FTS score outperformed EuroSCORE II (AUC $0.627,95 \%$ CI 0.613 to $0.641, \mathrm{p}<0.0001$ for DeLong test), Charlson comorbidity index (AUC $0.562,95 \%$ CI 0.548 to $0.576, \mathrm{p}<0.0001$ for DeLong test), and frailty index (AUC $0.486,95 \%$ CI 0.472 to $0.499, p<0.0001$ for DeLong test) for identifying futility (Figure 2). AUC for the FTS score
Table 1

Baseline characteristics in the derivation and validation populations treated with TAVI

\begin{tabular}{|c|c|c|c|}
\hline Variable & $\begin{array}{l}\text { Derivation } \\
(\mathrm{n}=10221)\end{array}$ & $\begin{array}{l}\text { Validation } \\
(\mathrm{n}=10222)\end{array}$ & $\mathrm{p}$ \\
\hline Age (years) & $82.5 \pm 7.0$ & $82.8 \pm 6.8$ & 0.002 \\
\hline Men & $5101(50 \%)$ & $5093(50 \%)$ & 0.91 \\
\hline Charlson comorbidity index & $5.0 \pm 2.9$ & $4.9 \pm 2.8$ & 0.05 \\
\hline Frailty index & $7.4 \pm 6.4$ & $7.2 \pm 6.2$ & 0.02 \\
\hline EuroSCORE II & $3.9 \pm 1.0$ & $3.9 \pm 1.0$ & 0.87 \\
\hline Heart failure & $6389(63 \%)$ & $6352(62 \%)$ & 0.59 \\
\hline History of pulmonary oedema & $711(7 \%)$ & $687(7 \%)$ & 0.5 \\
\hline Mitral regurgitation & $2093(21 \%)$ & $2065(20 \%)$ & 0.62 \\
\hline Aortic regurgitation & $1332(13 \%)$ & $1366(13 \%)$ & 0.48 \\
\hline Tricuspid regurgitation & $443(4 \%)$ & $416(4 \%)$ & 0.35 \\
\hline Coronary artery disease & $6447(63 \%)$ & $6521(64 \%)$ & 0.29 \\
\hline Previous myocardial infarction & $1550(15 \%)$ & $1591(16 \%)$ & 0.43 \\
\hline Dilated cardiomyopathy & $1809(18 \%)$ & $1768(17 \%)$ & 0.45 \\
\hline Hypertension & $8268(81 \%)$ & $8360(82 \%)$ & 0.1 \\
\hline Ischemic stroke & $560(6 \%)$ & $551(5 \%)$ & 0.78 \\
\hline Atrial fibrillation & $4897(48 \%)$ & $4991(49 \%)$ & 0.19 \\
\hline $\begin{array}{l}\text { Previous pacemaker or } \\
\text { Defibrillator }\end{array}$ & $2214(22 \%)$ & $2270(22 \%)$ & 0.35 \\
\hline Obesity & $2678(26 \%)$ & $2662(26 \%)$ & 0.8 \\
\hline Diabetes mellit & $3203(31 \%)$ & $3159(31 \%)$ & 0.5 \\
\hline Dyslipidaemia & $4834(47 \%)$ & $4813(47 \%)$ & 0.76 \\
\hline Smoker & $809(8 \%)$ & $799(8 \%)$ & 0.79 \\
\hline Vascular disease & $3983(39 \%)$ & $3941(39 \%)$ & 0.54 \\
\hline Abnormal renal function & $2116(21 \%)$ & $2014(20 \%)$ & 0.08 \\
\hline Liver disease & $625(6.1 \%)$ & $565(5.5 \%)$ & 0.07 \\
\hline Lung disease & $2743(27 \%)$ & $2771(27 \%)$ & 0.66 \\
\hline $\begin{array}{l}\text { Chronic obstructive pulmonary } \\
\text { disease }\end{array}$ & $1738(17 \%)$ & $1748(17 \%)$ & 0.85 \\
\hline Sleep apnoea syndrome & $942(9 \%)$ & $948(9 \%)$ & 0.89 \\
\hline Anaemia & $3131(31 \%)$ & $3078(30 \%)$ & 0.42 \\
\hline Previous cancer & $2050(20 \%)$ & $2015(20 \%)$ & 0.54 \\
\hline History of metastasis & $242(2 \%)$ & $218(2 \%)$ & 0.26 \\
\hline Alcohol related diagnoses & $480(5 \%)$ & $446(4 \%)$ & 0.25 \\
\hline Thyroid diseases & $1485(15 \%)$ & $1389(14 \%)$ & 0.05 \\
\hline HIV infection & $14(0.1 \%)$ & $9(0.1 \%)$ & 0.3 \\
\hline Cognitive impairment & $730(7 \%)$ & $675(7 \%)$ & 0.13 \\
\hline Depression & $1793(18 \%))$ & $1753(17 \%)$ & 0.46 \\
\hline Denutrition & $1351(13 \%)$ & $1244(12 \%)$ & 0.02 \\
\hline
\end{tabular}

Values are mean $(\mathrm{SD})$ or $\mathrm{n}(\%) . \mathrm{SD}=$ standard deviation; $\mathrm{TAVI}=$ transcatheter aortic valve replacement.

was 0.651 (95\% CI 0.637 to 0.665$)$ in the validation cohort where the FTS score similarly outperformed EuroSCORE II, Charlson comorbidity index and frailty index for identifying futility. The Hosmer-Lemeshow goodness of fit test had a p value of 0.87 suggesting that the model was accurate. The observed versus predicted risks of all-cause death during the first year post-TAVI within risk deciles are shown in Figure 3. We further divided the model arbitrarily into 3 groups with $11 \%, 22 \%$ and $43 \%$ futility, respectively. The low-risk group consisted of $47 \%$ of the patients and the high-risk group consisted of $7 \%$ of these patients (Table 4). Performance of the different strata of risk are in Table 4 with high specificity for the high-risk ( $>8$ points) strata. Survival curves for these 3 groups are shown in Figure 4.

Of note, we also evaluated our new score in some patients initially excluded of the analysis: the AUC) for the FTS score was 0.664 (95\% CI 0.641 to 0.685$)$ in patients 
Table 2

Baseline characteristics in the derivation population treated with TAVI

\begin{tabular}{|c|c|c|c|}
\hline \multirow[b]{2}{*}{ Variable } & \multicolumn{2}{|c|}{ Death during follow-up } & \multirow[b]{2}{*}{$\mathrm{p}$} \\
\hline & $\begin{array}{c}\text { No } \\
(\mathrm{n}=8375)\end{array}$ & $\begin{array}{c}\text { Yes } \\
(\mathrm{n}=1846)\end{array}$ & \\
\hline Age (years) & $82.5 \pm 7.0$ & $82.6 \pm 7.3$ & 0.63 \\
\hline Men & $4110(49 \%)$ & $991(54 \%)$ & 0.0003 \\
\hline Charlson comorbidity index & $4.9 \pm 2.9$ & $5.5 \pm 2.9$ & $<0.0001$ \\
\hline Frailty index & $7.5 \pm 6.6$ & $6.8 \pm 5.3$ & $<0.0001$ \\
\hline EuroSCORE II & $3.8 \pm 1.0$ & $4.2 \pm 1.1$ & $<0.0001$ \\
\hline Heart failure & $4982(60 \%)$ & $1407(76 \%)$ & $<0.0001$ \\
\hline History of pulmonary edema & $384(5 \%)$ & $327(18 \%)$ & $<0.0001$ \\
\hline Mitral regurgitation & $1656(20 \%)$ & $437(24 \%)$ & 0.0002 \\
\hline Aortic regurgitation & $1064(13 \%)$ & $268(15 \%)$ & 0.04 \\
\hline Tricuspid regurgitation & $339(4 \%)$ & $104(6 \%)$ & 0.002 \\
\hline Coronary artery disease & $5203(62 \%)$ & $1244(67 \%)$ & $<0.0001$ \\
\hline Previous myocardial infarction & $1173(14 \%)$ & $377(20 \%)$ & $<0.0001$ \\
\hline Dilated cardiomyopathy & $1402(17 \%)$ & $407(22 \%)$ & $<0.0001$ \\
\hline Hypertension & $6726(80 \%)$ & $1542(84 \%)$ & 0.001 \\
\hline Ischemic stroke & $421(5 \%)$ & $139(8 \%)$ & $<0.0001$ \\
\hline Atrial fibrillation & $3790(45 \%)$ & $1107(60 \%)$ & $<0.0001$ \\
\hline $\begin{array}{l}\text { Previous pacemaker or } \\
\text { Defibrillator }\end{array}$ & $1770(21 \%)$ & $444(24 \%)$ & 0.01 \\
\hline Obesity & $2149(26 \%)$ & $529(29 \%)$ & 0.01 \\
\hline Diabetes mellitus & $2543(30 \%)$ & $660(36 \%)$ & $<0.0001$ \\
\hline Dyslipidemia & $3938(47 \%)$ & $896(49 \%)$ & 0.24 \\
\hline Smoker & $632(8 \%)$ & $177(10 \%)$ & 0.003 \\
\hline Vascular disease & $3125(37 \%)$ & $858(47 \%)$ & $<0.0001$ \\
\hline Abnormal renal function & $1583(19 \%)$ & $533(29 \%)$ & $<0.0001$ \\
\hline Liver disease & $445(5 \%)$ & $180(10 \%)$ & $<0.0001$ \\
\hline Lung disease & $2124(25 \%)$ & $619(34 \%)$ & $<0.0001$ \\
\hline $\begin{array}{l}\text { Chronic obstructive pulmonary } \\
\text { disease }\end{array}$ & $1347(16 \%)$ & $391(21 \%)$ & $<0.0001$ \\
\hline Sleep apnea syndrome & $731(9 \%)$ & $211(11 \%)$ & 0.0003 \\
\hline Anaemia & $2404(29 \%)$ & $727(39 \%)$ & $<0.0001$ \\
\hline Previous cancer & $1568(19 \%)$ & $482(26 \%)$ & $<0.0001$ \\
\hline History of metastasis & $168(2 \%)$ & $74(4 \%)$ & $<0.0001$ \\
\hline Alcohol related diagnoses & $364(4 \%)$ & $116(6 \%)$ & 0.0004 \\
\hline Thyroid diseases & $1202(14 \%)$ & $283(15 \%)$ & 0.28 \\
\hline HIV infection & $12(0.1)$ & $2(0.1)$ & 0.71 \\
\hline Cognitive impairment & $573(7 \%)$ & $157(9 \%)$ & 0.01 \\
\hline Depression & $1390(17 \%)$ & $403(22 \%)$ & $<0.0001$ \\
\hline Denutrition & $1007(12 \%)$ & $344(19 \%)$ & $<0.0001$ \\
\hline
\end{tabular}

Values are mean $(\mathrm{SD})$ or $\mathrm{n}(\%) . \mathrm{SD}=$ standard deviation; TAVI $=$ transcatheter aortic valve replacement.

with transapical TAVI and 0.768 (95\% CI 0.761 to 0.775$)$ in those with surgical aortic valve replacement for identifying the risk of 1-year death.

\section{Discussion}

The FTS score showed a relatively good performance with high specificity to predict 1 -year survival. Using 3 risk categories, the FTS score assigned high risk of futility to $7 \%$ of the patients with a 1 -year death rate at $43 \%$.

European guidelines indicate that aortic valve replacement should be proposed to patients with a severe aortic stenosis with the exception of patients with an estimated survival of $<1$ year in whom the procedure is deemed futile. ${ }^{1,5}$ The present study shows that up to $18 \%$ of TAVI could be considered as futile in France, that is characterized by a survival $<1$ year, a percentage close to that reported
Table 3

Logistic regression model variables for all-cause death during first year of follow-up after TAVI in the derivation cohort

\begin{tabular}{|c|c|c|c|}
\hline & OR $(95 \% \mathrm{CI})$ & $\mathrm{p}$ & Points \\
\hline Gender (men) & $1.106(0.986-1.241)$ & 0.09 & \\
\hline Age (quartile) & $1.141(1.071-1.216)$ & $<0.0001$ & 1 \\
\hline Heart failure & $1.425(1.254-1.620)$ & $<0.0001$ & 1 \\
\hline History of pulmonary oedema & $3.288(2.780-3.889)$ & $<0.0001$ & 3 \\
\hline Mitral regurgitation & $0.993(0.868-1.136)$ & 0.92 & \\
\hline Aortic regurgitation & $0.993(0.850-1.160)$ & 0.93 & \\
\hline Tricuspid regurgitation & $1.144(0.895-1.463)$ & 0.28 & \\
\hline Coronary artery disease & $1.020(0.903-1.152)$ & 0.75 & \\
\hline Previous myocardial infarction & $1.156(0.979-1.364)$ & 0.09 & \\
\hline Dilated cardiomyopathy & $1.072(0.937-1.226)$ & 0.31 & \\
\hline Hypertension & $0.953(0.822-1.105)$ & 0.52 & \\
\hline Stroke & $1.342(1.088-1.655)$ & 0.006 & 1 \\
\hline Atrial fibrillation & $1.510(1.352-1.686)$ & $<0.0001$ & 1 \\
\hline $\begin{array}{l}\text { Previous pacemaker or } \\
\text { Defibrillator }\end{array}$ & $0.923(0.813-1.049)$ & 0.22 & \\
\hline Obesity & $0.989(0.869-1.126)$ & 0.87 & \\
\hline Diabetes mellitus & $1.101(0.977-1.241)$ & 0.12 & \\
\hline Dyslipidaemia & $0.914(0.815-1.024)$ & 0.12 & \\
\hline Smoker & $1.016(0.836-1.235)$ & 0.87 & \\
\hline Vascular disease & $1.158(1.017-1.318)$ & 0.03 & 1 \\
\hline Abnormal renal function & $1.310(1.154-1.487)$ & $<0.0001$ & 1 \\
\hline Liver disease & $1.409(1.142-1.740)$ & 0.001 & 1 \\
\hline Lung disease & $1.338(1.130-1.584)$ & 0.001 & 1 \\
\hline $\begin{array}{l}\text { Chronic obstructive pulmonary } \\
\text { disease }\end{array}$ & $0.894(0.734-1.088)$ & 0.26 & \\
\hline Sleep apnoea syndrome & $1.091(0.908-1.311)$ & 0.35 & \\
\hline Anaemia & $1.196(1.066-1.343)$ & 0.002 & 1 \\
\hline Cancer within preceding 5 y & $1.308(1.146-1.494)$ & $<0.0001$ & 1 \\
\hline History of metastasis & $1.733(1.268-2.369)$ & 0.001 & 2 \\
\hline Alcohol related diagnoses & $1.027(0.795-1.326)$ & 0.84 & \\
\hline Thyroid diseases & $0.873(0.750-1.018)$ & 0.08 & \\
\hline HIV infection & $0.768(0.161-3.662)$ & 0.74 & \\
\hline Cognitive impairment & $1.013(0.831-1.235)$ & 0.90 & \\
\hline Depression & $1.221(1.068-1.397)$ & 0.003 & 1 \\
\hline Denutrition & $1.257(1.087-1.454)$ & 0.002 & 1 \\
\hline
\end{tabular}

TAVI $=$ transcatheter aortic valve replacement. $*$ age quartile: 1 point when age $>80$ points, 2 points when age $>84,3$ points when age $>87$.

by Hioki et al. ${ }^{18}$. While the predictable increase of TAVI procedures will mainly concern low-risk patients owing to the results of the Partner 3 trial, ${ }^{19}$ the issue of futile interventions will remain because of population aging. The combination of simple clinical variables in the FTS score fairly predicts futility; in particular, the $7 \%$ of patients with a high-risk FTS score ( $>8$ points) had an observed death rate of more than $40 \%$ that is very close to that of severe aortic stenosis medically treated. ${ }^{20}$ The FTS score emphasizes the importance of comorbidities, lung and kidney disease and also of clinical presentation with an history of heart failure; it had a better predictive performance than the Charlson comorbidity index. The performance of the FTS score appeared similar to that of the CAPRI score (AUC of 0.67 vs 0.68 ), albeit it could not be directly compared owing to the nature of the collection of the data (the CTs were not available for analysis in this cohort). It has the advantages of encompassing important comorbidities and of being easy to use. Conversely, the relatively "rough" nature of some of the variables embedded in the FTS score 


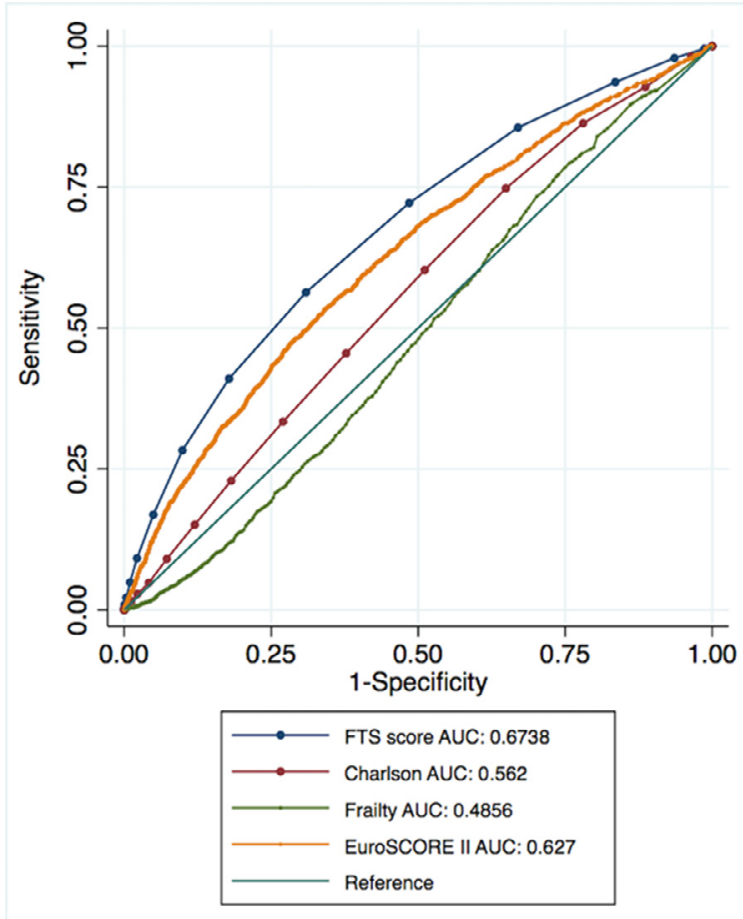

Figure 2. Receiver operating curves of the derivation model for FTS score, EuroSCORE II, Charlson comorbidity index and frailty index for identifying death at one year after TAVI in the derivation cohort.

may constitute a factor of variability. This is particularly the case for vascular disease, an important predictor of postTAVI outcomes. ${ }^{6,21}$ In the FTS score, vascular disease is present as a generic component while, in the CAPRI score, it is precisely assessed from the CT-scan. Whether this could make the FTS score less transposable to other populations deserves further studies. Frailty is another important issue for TAVI candidates. Using the Hospital Frailty Risk Score (HFRS), Kundi et al. showed that 1-year mortality rate reached $30.1 \%$ in individuals undergoing TAVI categorized as high risk with HFRS. ${ }^{22}$ The present study showed that the FTS score outperformed this frailty index. Finally, STS and EuroSCORE II are known to be poorly predictive of 1-year survival ${ }^{5}$ what is confirmed for the Euroscore II in the present study. Albeit the FTS score surpassed the other scores in the present study, its performance appeared slightly worse than that of a futility score proposed by Zusman et al. (AUC 0.71). However, they considered a far smaller mono-centric patient-cohort and a composite outcome (mortality, stroke, lack of functional-class improvement, and readmissions at 1 year). ${ }^{23}$ One has to realize that predicting death is difficult and that all scores, including the present one, exhibit only moderate diagnostic performance with AUC $\leq 0.7$. This suggests that exceeding this threshold will probably be difficult using classical methods if one wants to stay reasonable in terms of variables included. There may be a case for artificial intelligence and machine learning. ${ }^{24}$ In any case and although there is still room for clinical judgment within the Heart team, an imperfect score is probably better than no score at all to help the decisionmaking process. In this respect, no score will provide a "go-no-go" criteria; yet the FTS score could provide a more objective tool among a bunch of others to proceed to TAVI. The calculator of the FTS score and its performance are summarized in Figure 4.

Some limitations should be acknowledged. A main limitation is inherent to the retrospective, observational nature of the study. Further, the study was based on administrative data, with limitations inherent to such methodology. The PMSI database contains diagnoses coded using ICD-10, which are obtained at hospital discharge and are the physician's responsibility. Data were not systematically externally checked and this could have caused information bias. Some minor diagnoses may have been underreported in the database because of a lack of incentive for the hospital to exhaustively report every one, while others may have been misclassified. However, the large scale of the database is

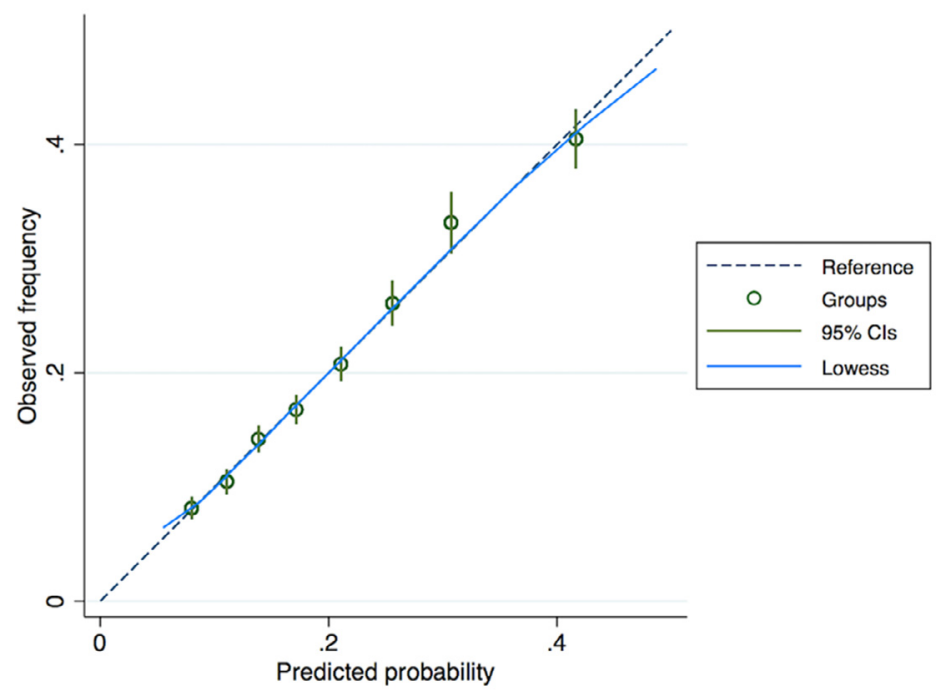

Figure 3. Calibration plots of the futility risk model in the derivation cohort. The diagonal line represents perfect calibration. Calibration of the futility prediction score is very good until a predicted in-hospital mortality rate of approximately $50 \%$. Vertical bars represent $95 \%$ CIs. 
Table 4

Rate of futility (all-cause mortality in the first year after TAVI procedure) with sensitivity and specificity by different risk strata of the TAVI futility score in the derivation cohort

\begin{tabular}{|c|c|c|c|c|c|c|c|c|c|}
\hline TAVI futility score & $\begin{array}{c}\text { Alive at } 1 \text { year } \\
\mathrm{N}(\% \text { in the strata) }\end{array}$ & $\begin{array}{c}\text { Dead at } 1 \text { year } \\
\mathrm{N}(\% \text { in the strata })\end{array}$ & $\begin{array}{c}\text { Total } \\
\mathrm{N}(\% \text { in the population })\end{array}$ & $\begin{array}{l}\text { Cut } \\
\text { point }\end{array}$ & Sensitivity & Specificity & $\begin{array}{l}\text { Correctly } \\
\text { classified }\end{array}$ & $\mathrm{LR}+$ & LR- \\
\hline Low $[0-4$ points $]$ & $\begin{array}{l}4,314 \\
(89.4)\end{array}$ & $\begin{array}{c}514 \\
(10.7)\end{array}$ & $\begin{array}{l}4,828 \\
(47.2)\end{array}$ & $\leq 4$ & $100.00 \%$ & $0.00 \%$ & $18.08 \%$ & 1 & \\
\hline High-risk [ $>8$ points] & $\begin{array}{c}416 \\
(57.1)\end{array}$ & $\begin{array}{c}312 \\
(42.9)\end{array}$ & $\begin{array}{l}728 \\
(7.1)\end{array}$ & $>8$ & $16.88 \%$ & $95.03 \%$ & $80.90 \%$ & 3.3981 & 0.8746 \\
\hline
\end{tabular}

Different risk strata of the TAVI futility score are as follows: Low [0-4 points], Medium [5-8 points], High-risk [ $>8$ points]). LR $+=$ positive likelihood ratio; $\mathrm{LR}-=$ negative likelihood ratio.
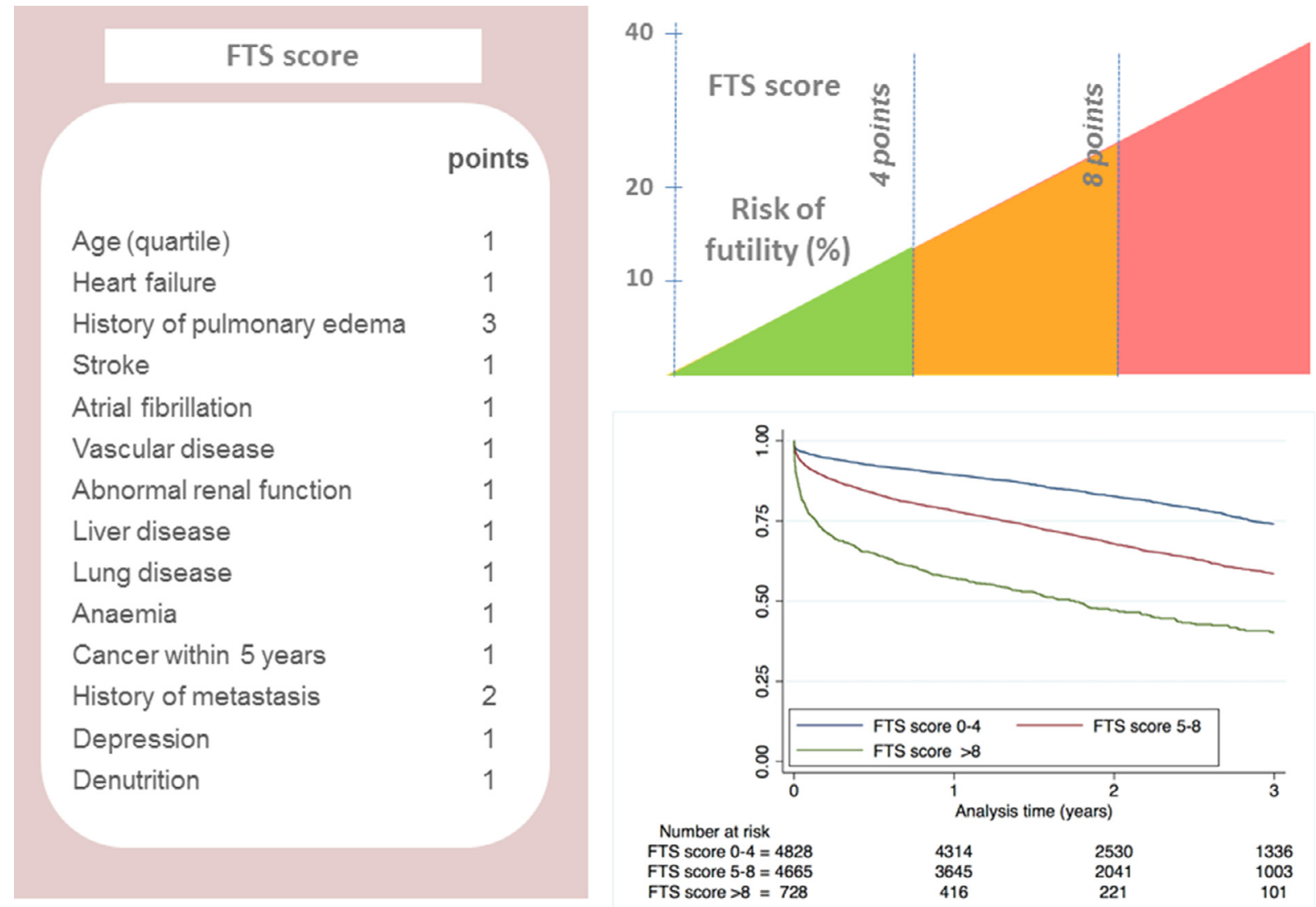

Figure 4. Kaplan-Meier Curves of total mortality during follow-up regarding 3 risk strata (Low [0-4 point], Medium [5-8 points], High-risk [ $>8$ points]). For FTS score calculation, age quartiles are as follows: 1 point when age $>80$ points, 2 points when age $>84,3$ points when age $>87$.

likely to compensate this bias and, as coding of complications is linked to reimbursement and is regularly controlled, it is expected to be of good quality. Patients from the present study actually showed prevalences of chronic diseases close to those reported in other observational studies. ${ }^{25,26}$ The analysis was limited to deaths that occurred during hospitalization. However, French data show that hospital deaths account for a majority of all deaths in patients similar to the mean age of our population. ${ }^{27}$ Our large population of patients admitted for a TAVI procedure likely represents a heterogeneous group of patients admitted with various kinds of illnesses and severities, which may have affected prognosis. Our analysis was restricted to the variables present in the database, which meant that characteristics such as mean gradient, valve area and calcification were not available for analysis. Another limitation is the lack of information on antithrombotic drug use, as drug therapies were not available in the database. This bias is possibly controlled by a systematic use of similar antithrombotic strategies after TAVI based on current guidelines. ${ }^{1,2}$

In conclusion, the FTS is a simple and efficient score that may facilitate identification of patients who, despite an 
apparently successful procedure, have a risk of death that may outweigh the benefit anticipated with TAVI.

\section{Declaration of Interests}

CSE reports honoraria from Abbott and Biotronik. DA has received fees for lectures or consulting from Amgen, Sanofi, Novartis, AstraZeneca, Bayer, Bristol-Myers Squibb, Boehringer-Ingelheim, MSD, Pfizer, and Servier. LF reports consultant or speaker activities for Bayer, BMS/ Pfizer, Boehringer-Ingelheim, Medtronic, and Novartis. TB reports consultant activities for Edwards Lifesciences. All other authors declare no competing interests.

\section{Authors' Contribution}

Pierre Lantelme: planning, writing, original draft, guarantor; Thibaut Lacour: ressources, database management; Arnaud Bisson: ressources, database management, statistical analysis; Julien Herbert: ressources; Fabrice Ivanes: ressources, drafting the manuscript; Thierry Bourguignon: critical reading of the manuscript; Laurent Quilliet: planning, critical reading of the manuscript; Denis Angoulvant: critical reading of the manuscript; Brahim Harbaoui: ressources, data management; Dominique Babuty: ressources, final reading of the manuscript; Christophe Saint Etienne: critical reading of the manuscript; Pierre Deharo: planning, critical reading of manuscript; Anne Bernard: writing, critical reading, final reading; Laurent Fauchier: planning, statistical analysis, writing, guarantor.

\section{Supplementary materials}

Supplementary material associated with this article can be found in the online version at https://doi.org/10.1016/j. amjcard.2020.05.043.

1. Baumgartner H, Falk V, Bax JJ, De Bonis M, Hamm C, Holm PJ, Iung B, Lancellotti P, Lansac E, Rodriguez Munoz D, Rosenhek R, Sjogren $\mathrm{J}$, Tornos Mas P, Vahanian A, Walther T, Wendler O, Windecker S, Zamorano JL. 2017 ESC/EACTS guidelines for the management of valvular heart disease. Eur Heart J 2017;38:2739-2791.

2. Nishimura RA, Otto CM, Bonow RO, Carabello BA, Erwin JP 3rd, Fleisher LA, Jneid H, Mack MJ, McLeod CJ, O'Gara PT, Rigolin VH, Sundt TM 3rd, Thompson A. 2017 AHA/ACC focused update of the 2014 AHA/ACC guideline for the management of patients with valvular heart disease: a report of the American College of Cardiology/ American Heart Association task force on clinical practice guidelines. J Am Coll Cardiol 2017;70:252-289.

3. Otto CM, Kumbhani DJ, Alexander KP, Calhoon JH, Desai MY, Kaul S, Lee JC, Ruiz CE, Vassileva CM. 2017 ACC expert consensus decision pathway for transcatheter aortic valve replacement in the management of adults with aortic stenosis: a report of the American College of Cardiology task force on clinical expert consensus documents. J Am Coll Cardiol 2017;69:1313-1346.

4. Kirkpatrick JN, Hauptman PJ, Swetz KM, Blume ED, Gauvreau K, Maurer M, Goodlin SJ. Palliative care for patients with end-stage cardiovascular disease and devices: a report from the palliative care working group of the geriatrics section of the American College of Cardiology. JAMA Intern Med 2016;176:1017-1019.

5. Lantelme P, Eltchaninoff H, Rabilloud M, Souteyrand G, Dupre M, Spaziano M, Bonnet M, Becle C, Riche B, Durand E, Bouvier E, Dacher JN, Courand PY, Cassagnes L, Davila Serrano EE, Motreff P, Boussel L, Lefevre T, Harbaoui B. Development of a risk score based on aortic calcification to predict 1-year mortality after transcatheter aortic valve replacement. JACC Cardiovasc Imaging 2019;12:123132 .

6. Harbaoui B, Montoy M, Charles P, Boussel L, Liebgott H, Girerd N, Courand PY, Lantelme P. Aorta calcification burden: towards an integrative predictor of cardiac outcome after transcatheter aortic valve implantation. Atherosclerosis 2016;246:161-168.

7. Chantry AA, Deneux-Tharaux C, Cans C, Ego A, Quantin C, BouvierColle MH, GRACE study group. Hospital discharge data can be used for monitoring procedures and intensive care related to severe maternal morbidity. J Clin Epidemiol 2011;64:1014-1022.

8. Lorgis L, Cottenet J, Molins G, Benzenine E, Zeller M, Aube H, Touzery C, Hamblin J, Gudjoncik A, Cottin Y, Quantin C. Outcomes after acute myocardial infarction in HIV-infected patients: analysis of data from a French nationwide hospital medical information database. Circulation 2013;127:1767-1774.

9. Fauchier L, Clementy N, Pelade C, Collignon C, Nicolle E, Lip GY. Patients with ischemic stroke and incident atrial fibrillation: a nationwide cohort study. Stroke 2015;46:2432-2437.

10. Nguyen V, Michel M, Eltchaninoff H, Gilard M, Dindorf C, Iung B, Mossialos E, Cribier A, Vahanian A, Chevreul K, Messika-Zeitoun D. Implementation of transcatheter aortic valve replacement in france. $J$ Am Coll Cardiol 2018;71:1614-1627.

11. Deharo P, Bisson A, Herbert J, Lacour T, Saint Etienne C, Grammatico-Guillon L, Porto A, Collart F, Bourguignon T, Cuisset T, Fauchier $\mathrm{L}$. Impact of sapien 3 balloon-expandable versus evolut $\mathrm{R}$ self-expandable transcatheter aortic valve implantation in patients with aortic stenosis: data from a nationwide analysis. Circulation 2020;141:260268.

12. Nashef SA, Roques F, Sharples LD, Nilsson J, Smith C, Goldstone AR, Lockowandt U. EuroSCORE II. Eur J Cardio-Thorac Surg 2012;41:734-744. discussion 744-735.

13. Charlson M, Szatrowski TP, Peterson J, Gold J. Validation of a combined comorbidity index. J Clin Epidemiol 1994;47:12451251.

14. Gilbert T, Neuburger J, Kraindler J, Keeble E, Smith P, Ariti C, Arora S, Street A, Parker S, Roberts HC, Bardsley M, Conroy S. Development and validation of a hospital frailty risk score focusing on older people in acute care settings using electronic hospital records: an observational study. Lancet 2018:391:1775-1782.

15. Kappetein AP, Head SJ, Genereux P, Piazza N, van Mieghem NM, Blackstone EH, Brott TG, Cohen DJ, Cutlip DE, van Es GA, Hahn RT, Kirtane AJ, Krucoff MW, Kodali S, Mack MJ, Mehran R, RodesCabau J, Vranckx P, Webb JG, Windecker S, Serruys PW, Leon MB. Updated standardized endpoint definitions for transcatheter aortic valve implantation: the valve academic research consortium- 2 consensus document. Eur Heart J 2012;33:2403-2418.

16. Lloyd-Jones DM, Wang TJ, Leip EP, Larson MG, Levy D, Vasan RS, D’Agostino RB, Massaro JM, Beiser A, Wolf PA, Benjamin EJ. Lifetime risk for development of atrial fibrillation: the framingham heart study. Circulation 2004;110:1042-1046.

17. Mehta HB, Mehta V, Girman CJ, Adhikari D, Johnson ML. Regression coefficient-based scoring system should be used to assign weights to the risk index. J Clin Epidemiol 2016;79:22-28.

18. Hioki H, Watanabe Y, Kozuma K, Nara Y, Kawashima H, Nagura F, Nakashima M, Kataoka A, Yamamoto M, Naganuma T, Araki M, Tada N, Shirai S, Yamanaka F, Hayashida K. Timing of susceptibility to mortality and heart failure in patients with preexisting atrial fibrillation after transcatheter aortic valve implantation. Am $J$ Cardiol 2017; 120:1618-1625.

19. Mack MJ, Leon MB, Thourani VH, Makkar R, Kodali SK, Russo M, Kapadia SR, Malaisrie SC, Cohen DJ, Pibarot P, Leipsic J, Hahn RT, Blanke P, Williams MR, McCabe JM, Brown DL, Babaliaros V, Goldman S, Szeto WY, Genereux P, Pershad A, Pocock SJ, Alu MC, Webb JG, Smith CR, PARTNER 3 Investigators. Transcatheter aortic-valve replacement with a balloon-expandable valve in low-risk patients. $N$ Engl J Med 2019. [Epub ahead of print].

20. Gonzalez-Saldivar H, Rodriguez-Pascual C, de la Morena G, Fernandez-Golfin C, Amoros C, Alonso MB, Dolz LM, Sole AA, GuzmanMartinez G, Gomez-Doblas JJ, Jimenez AA, Fuentes ME, Gay LG, Ortiz MR, Avanzas P, Abu-Assi E, Ripoll-Vera T, Diaz-Castro O, Osinalde EP, Martinez-Selles M. Comparison of 1-year outcome in patients with severe aorta stenosis treated conservatively or by aortic valve replacement or by percutaneous transcatheter aortic valve 
implantation (data from a multicenter spanish registry). Am J Cardiol 2016;118:244-250.

21. Bouleti C, Himbert D, Iung B, Alos B, Kerneis C, Ghodbane W, Messika-Zeitoun D, Brochet E, Fassa AA, Depoix JP, Ou P, Nataf P, Vahanian A. Long-term outcome after transcatheter aortic valve implantation. Heart 2015;101:936-942.

22. Kundi H, Popma JJ, Reynolds MR, Strom JB, Pinto DS, Valsdottir LR, Shen C, Choi E, Yeh RW. Frailty and related outcomes in patients undergoing transcatheter valve therapies in a nationwide cohort. Eur Heart J 2019;40:2231-2239.

23. Zusman O, Kornowski R, Witberg G, Lador A, Orvin K, Levi A, Assali A, Vaknin-Assa H, Sharony R, Shapira Y, Sagie A, Landes U. Transcatheter aortic valve implantation futility risk model development and validation among treated patients with aortic stenosis. Am J Cardiol 2017;120:2241-2246.

24. Hernandez-Suarez DF, Kim Y, Villablanca P, Gupta T, Wiley J, NievesRodriguez BG, Rodriguez-Maldonado J, Feliu Maldonado R, da Luz Sant'Ana I, Sanina C, Cox-Alomar P, Ramakrishna H, Lopez-Candales A, O'Neill WW, Pinto DS, Latib A, Roche-Lima A. Machine learning prediction models for in-hospital mortality after transcatheter aortic valve replacement. JACC Cardiovasc Interv 2019;12:1328-1338.
25. Didier R, Eltchaninoff H, Donzeau-Gouge P, Chevreul K, Fajadet J, Leprince $\mathrm{P}$, Leguerrier A, Lievre M, Prat A, Teiger E, Lefevre T, Tchetche D, Carrie D, Himbert D, Albat B, Cribier A, Sudre A, Blanchard D, Rioufol G, Collet F, Houel R, Dos Santos P, Meneveau N, Ghostine S, Manigold T, Guyon P, Cuisset T, Le Breton H, Delepine S, Favereau X, Souteyrand G, Ohlmann P, Doisy V, Lognone T, Gommeaux A, Claudel JP, Bourlon F, Bertrand B, Iung B, Gilard M. Five-year clinical outcome and valve durability after transcatheter aortic valve replacement in highrisk patients. Circulation 2018;138:2597-2607.

26. Vlastra W, Chandrasekhar J, Munoz-Garcia AJ, Tchetche D, de Brito FS Jr., Barbanti M, Kornowski R, Latib A, D’Onofrio A, Ribichini F, Baan J, Tijssen JGP, Trillo-Nouche R, Dumonteil N, Abizaid A, Sartori S, D'Errigo P, Tarantini G, Lunardi M, Orvin K, Pagnesi M, Del Valle R, Modine T, Dangas G, Mehran R, Piek JJ, Delewi R. Comparison of balloon-expandable vs. self-expandable valves in patients undergoing transfemoral transcatheter aortic valve implantation: from the CENTER-collaboration. Eur Heart J 2019;40:456-465.

27. Gisquet E, Aouba A, Aubry R, et al. Where do we die in France? Analysis of death certificates (1993-2008). Bulletin Epidemiologique Hebdomadaire 2012. 